\title{
Development and validation of a social cognitive theory-based survey for elementary nutrition education program
}

\author{
Elisha Hall ${ }^{1}$, Weiwen Chai ${ }^{1}$, Wanda Koszewski ${ }^{2}$ and Julie Albrecht ${ }^{*}$
}

\begin{abstract}
Background: The Social Cognitive Theory (SCT) is a widely used model for developing elementary nutrition education programs; however, few instruments are available to assess the impact of such programs on the main constructs of the SCT. The purposes of this study were: 1) to develop and validate a SCT-based survey instrument that focuses on knowledge, behavior, and self-efficacy for fifth grade students; 2) to assess the relationships between knowledge, behavior, and self-efficacy; and 3) to assess knowledge, behavior, and self-efficacy for healthy eating among the fifth grade students.

Methods: A 40-item instrument was developed and validated using content validity and tested among 98 fifth grade students for internal consistency reliability. Relationships between knowledge, behavior, and self-efficacy were assessed using Pearson Correlation Coefficients. Differences in behavior and knowledge scores between children with high and low self-efficacy were examined using t-test.
\end{abstract}

Results: Cronbach's alphas for self-efficacy (0.70) and behavior (0.71) subscales of the survey were acceptable, although lower for knowledge (0.56). Summary scores for self-efficacy and behaviors were positively correlated $(r=0.40, P=0.0001)$; however, summary knowledge scores were not associated with self-efficacy $(r=0.02, P=0.88)$ or behavior scores $(r=0.14$, $P=0.23)$. Participants with high self-efficacy also had significantly higher scores on consuming fruits $(P=0.0009)$ and dairy products $(P=0.009)$, eating breakfast $(P=0.008)$, helping plan family meals $(P=0.0006)$ and total behaviors for healthy-eating $(P=0.001)$ compared to those with low self-efficacy. In addition, approximately two thirds of the fifth grade students reported that they did not eat any fruits or vegetables or ate them only once on a typical day.

Conclusions: The developed instrument is a reliable and useful tool to assess SCT-based elementary nutrition education programs, particularly for self-efficacy and behavior. Our results also indicated that strategic interventions are necessary to improve dietary behaviors regarding fruit and vegetable consumptions among elementary school students.

Keywords: Validation, Social cognitive theory, Behavior, Self-efficacy, Knowledge, Healthy eating, Elementary nutrition education

\section{Background}

Childhood obesity is a serious issue in the United States that affects approximately $17 \%$ of youth ages $2-19$ years old [1]. These rates are concerning for the current generation due to the many health complications that can affect these children, and have the potential to lead into adulthood [2,3]. The school environment is one of the main target areas for children to develop healthy

\footnotetext{
* Correspondence: jalbrecht1@unl.edu

'Department of Nutrition and Health Sciences, University of

Nebraska-Lincoln, 110 Leverton Hall, Lincoln, NE 68583, USA

Full list of author information is available at the end of the article
}

behaviors. Various interventions have been conducted within schools, focusing on nutrition and/or physical activity.

The Social Cognitive Theory (SCT) is one of the widely used models for developing such programs. This theory emphasizes that human behavior depends on the reciprocal interaction of personal, behavioral, and environmental factors [4]. Several interventions grounded in the SCT among 4-6 year old children have demonstrated positive outcomes in creating significant changes in healthy eating and/or physical activity [5]. In adolescents, school-based interventions have resulted in decreased sedentary 
behaviors and increased physical activity [6,7]. After-school programs, using SCT-based invention also showed improvements in nutrition behaviors such as intakes of fruits and vegetables, healthy snacks, water, and sugar-free beverages and physical activity among 8-13 year old children $[8,9]$. Outside of the school environment, significant behavioral improvements were also observed among preadolescents and adolescents after the completion of SCT-based nutrition and/or physical activity interventions [10-12].

Several existing survey instruments on nutrition and physical activity primarily measure knowledge and behavior [13-16], but few assess self-efficacy which is a significant component of the SCT [17]. The most cited self-efficacy items for nutrition interventions among elementary school children were created by the Gimme 5 program [14] and "Smart Bodies" [18]; however, both programs exclusively focused on fruits and vegetables. In addition, the self-efficacy component from the AfterSchool Student Questionnaire, modified from the Health Behavior Questionnaire, focuses only on dietary behaviors related to sodium and fat intake $[15,19]$.

With the increasing need for theory-based intervention programs that target behavior changes [20], a valid and useful measurement tool is needed to assess the impact of SCT-based nutrition interventions on the main constructs of the theory, particularly self-efficacy. Contento et al. conducted a review of instruments for nutrition education programs, suggesting that the measurement tools should reflect the study design, intervention, and objectives while still having substantial validity and reliability [21]. Furthermore, according to the SCT, knowledge of health risks and benefits is a construct that creates the precondition for change $[17,22]$. Behavioral capacity, another construct of the SCT, is composed of the knowledge and skills necessary to perform a health behavior [23,24]; however, beliefs of self-efficacy are needed for most people to overcome the barriers to adopting and maintaining healthy lifestyle habits [17]. Therefore, the purposes of this pilot study were: 1) to develop and validate a SCT-based survey instrument that focuses on knowledge, behavior, and self-efficacy for fifth grade students; 2) to assess the relationships between knowledge, behavior, and selfefficacy, the main constructs of the SCT; and 3) to assess knowledge, behavior, and self-efficacy for healthy eating among the fifth grade students.

\section{Methods}

\section{Participants and procedures}

This investigation was approved by the University of Nebraska Internal Review Board. A total of 98 fifth grade students (aged 9-12 years) were recruited from four local elementary schools which had never been exposed to any supplementary nutrition education curriculum and had various numbers of students receiving free and reduced price meals (6.5-47.3\%). Surveys were administered in the students' regular classrooms. Students were directed to answer each question to the best of their ability, and if at any point they did not understand a word or question or what a question was asking, or were confused for any other reason, to circle what was confusing on the survey and write why it confused them. Parent consent and youth assent for each participant were obtained before the data collection.

\section{Survey instrument construction and scoring}

The current instrument, The Healthy Habits Survey, was developed to assess the long-term impact for Growing Healthy Kids (GHK), a SCT-based, nutrition and physical activity curriculum for elementary students. The instrument utilizes the constructs of knowledge, behavior and selfefficacy with topic areas including digestion, physical activity, healthy meals, healthy snacking, food groups, breakfast, and meal planning, which were applicable to material covered in GHK. Items on the survey were selected or modified from the following programs or instruments: KidQuest [25], Network for a Healthy California Youth Survey [26], Nutrition Education Program [27], SIRK [26], CATCH [13], and PizzaPlease [28]. Certain knowledge questions and all self-efficacy questions were created as existing knowledge and self-efficacy items did not address topics relevant to GHK. The combination of existing and new items generated a 77-item instrument. The reading level was found to be appropriate for the fifth grade level based on a combination of common readability indicators [29].

For behavior questions, the responses to the items were scored from 1 to 4 (or 1 to 5 if there were 5 responses to the question) with a higher score reflecting a more positive response. Items were reversely scored when questions were related to an unhealthy behavior. Similarly, items for self-efficacy were scored from 1 to 3 , indicating low, medium, and high self-efficacy, respectively. For each of the knowledge items, "1" was given if the participant had the correct answer, and if not, "0" was marked for the item.

\section{Content validation of survey instrument}

Content and face validation [30] were used to validate the survey instrument. Initially, the survey included 77 items focusing on knowledge, behavior, and self-efficacy. Two content experts reviewed and reduced the survey to 68 items. The survey was then validated using an additional nine nutrition experts (content validation) and three lay experts (face validation). The nine content experts were Extension educators, assistants, and program leaders involved with implementing school-based nutrition and physical activity curriculum, of which five were Registered Dietitians and seven had Master degrees or higher. 
For content validation, all experts received a cover letter, an instruction sheet, and a draft of the survey instrument. The cover letter provided an overview and the purpose of the study, asking each expert for their input on the survey. Experts were asked to independently rate each survey item on a 1 to 4 scale based on two validity factors: relevance and clarity [30]. Relevance referred to the item's ability to represent the lessons covered through GHK ( 1 = the survey item is not representative, $2=$ major revisions are needed to be representative, $3=$ minor revisions are needed to be representative, $4=$ the survey item is representative). Clarity represented how clearly the item was worded ( $1=$ the item is not clear, $2=$ major revisions are needed to be clear, $3=$ minor revisions are needed to be clear, $4=$ item is clear). Experts were also asked to provide additional comments addressing repetition, difficulty, appropriateness to income level, what was unclear about any question, and general suggestions they had on each item. An average rating of relevance and clarity for each item was calculated. Items scoring less than 3.0 in the relevance or clarity category were removed from the instrument. Items scoring between 3.0 -4.0 were either removed or edited based on handwritten comments from the experts. Face validity was conducted among three fifth grade teachers (lay experts) who gave qualitative feedback on the survey.

\section{Data analysis}

For quantitative validation data, mean relevance and clarity scores were calculated respectively, based on the nine experts' average ratings. The internal consistency/reliability for each section (knowledge, behavior and self-efficacy) was analyzed using Cronbach's alpha with a value of 0.60 or higher deemed as acceptable [21]. Qualitative data for content validation and pilot testing were transcribed, coded, and grouped into reoccurring comments or themes for each item identified.

The scores of each participant's responses to selfefficacy questions regarding healthy eating in the survey were summarized and the median value was identified by ranking all of the participants based on their summary scores (total self-efficacy scores). After excluding individuals with the median value of summary selfefficacy scores $(n=19)$, the remaining participants were stratified into "high self-efficacy" and "low self-efficacy" groups based on the following criteria: high self-efficacy group, summary self-efficacy scores $>$ median value; low self-efficacy group, summary self-efficacy scores $<$ median value. In addition, each subject's scores for healthy eating related behavior questions and knowledge items were totaled. Differences in means of summary and individual behavior scores and summary knowledge scores between the two groups (high self-efficacy vs. low selfefficacy group) were examined using t-test. The relations between behavior, self-efficacy, and knowledge summary scores were assessed using Pearson Correlation Coefficient.

Due to the multi-dimensional nature of the constructs, factor analysis was used to identify underlying main factors/patterns associated with behavior or self-efficacy variables, with the assumption that participants responded similarly to certain questions which are all associated with a latent variable (factor). SPSS 22 (SPSS, Inc, Chicago, IL) was used for all statistical analyses with a two-sided $p$ value of $<0.05$ considered statistically significant.

\section{Results}

\section{Content and face validity}

Qualitative comments from the nine experts are presented in Table 1. Four items in the relevance category had an average score of $<3.0$ and were removed from the scale. Among the 64 items that scored between 3.0 - 4.0 in the relevance category, 38 were removed and 17 were edited based on handwritten comments addressing repetition, difficulty, appropriateness to income level, and general suggestions. Seven items in the clarity category had an average score of $<3.0$ and were removed from the scale (three of which had already been targeted for removal due to low relevance scores). Sixty-one items had scores between 3.0 - 4.0 and were edited based on comments indicating what was unclear about each question. Seven additional items were added to compensate for removed items. The final survey instrument used in pilot testing contained 37 items including sections of demographics (4), knowledge (11), behavior (12), and self-efficacy (10). Results reported in the current study for our pilot participants were based upon this 37 -item survey. For face validity, the qualitative feedback from the three fifth grade teachers varied; however, the disagreements appeared to focus on the knowledge questions and were not consistent enough to warrant further editing (Table 1).

\section{Pilot testing and internal consistency}

All fifth grade students $(\mathrm{n}=98)$ completed the survey instrument, which took approximately 30 minutes. Cronbach's alpha for knowledge was 0.41 and increased to 0.56 after removing items with low reliability. Qualitative results from student feedback showed difficulty in understanding words such as "carbohydrate" and "vitamin" although these items were validated at a fifth grade level. Therefore, knowledge items were primary replaced with alternate published items at a lower level of difficulty $[25,27,28]$, but still rated at a fifth grade level.

Cronbach's alphas for behavior and self-efficacy were 0.60 and 0.67 , respectively. The corresponding values were increased to 0.71 and 0.70 when the items with low reliability were excluded. Removal of some behavior questions necessitated the addition of published beverage items [26] to address topics that were eliminated 
Table 1 Summary of comments from content experts $(n=9)$ for content validity and lay experts $(n=3)$ for face validity

\begin{tabular}{|c|c|}
\hline Themes & Quotes \\
\hline \multicolumn{2}{|l|}{ Content validity results $(n=9)$} \\
\hline \multirow[t]{3}{*}{ Repetition } & "Question may not be necessary." \\
\hline & "Only need $1-2$ of these types of questions." \\
\hline & "Repetitive." \\
\hline \multirow[t]{3}{*}{ Difficulty } & "Whole grains are sometimes hard for them to understand." \\
\hline & "They won't know what these are." \\
\hline & "These choices will be a bit confusing." \\
\hline \multirow[t]{4}{*}{ Appropriateness to income level } & "Our students do skip meals but not because they want to, because they do not have food." \\
\hline & "This is the parent's responsibility not the child's." \\
\hline & $\begin{array}{l}\text { "I think \#12 may make some students feel bad or sad that they do not participate especially if it is because of } \\
\text { money. It may not be a choice for the kids." }\end{array}$ \\
\hline & "This question could make students feel bad about being in a low income family." \\
\hline \multicolumn{2}{|l|}{ Face validity results $(n=3)$} \\
\hline \multirow[t]{3}{*}{ Too Difficult } & "I couldn't answer some of these vitamin questions myself." \\
\hline & "I don't know if students can answer all of these questions [pointing to vitamin questions]." \\
\hline & "We don't teach all of these topics here, so they probably won't know some of this stuff." \\
\hline \multirow[t]{3}{*}{ Appropriate for grade level } & "These all look good." \\
\hline & "All of these are appropriate for the grade level." \\
\hline & "I don't think students would have difficulty with any of these questions." \\
\hline
\end{tabular}

Note: Content validity was conducted using 9 content experts and face validity was conducted using $35^{\text {th }}$ grade teachers (lay experts).

due to low reliability. This led to a final, fully developed survey instrument (which will be used to assess the Growing Healthy Kids nutrition education curriculum) that included 40 items with basic demographics (3 items) and knowledge (14 items), behavior (12 items), and self-efficacy (11 items) assessing the following topics: healthy meals, food groups, healthy snacking, healthy beverages, physical activity, breakfast, daily recommendation, and meal planning. The added items (e.g., knowledge items on food groups and daily recommendations) in the final survey were not re-tested since they were validated previously. Furthermore, notes from qualitative observations while students completed the survey indicated that 1) Students rushed to complete survey; 2) students failed to complete the entire survey; or 3) Students had difficulty with demographic questions.

\section{Demographics, behaviors, self-efficacy, and knowledge} Among 98 fifth grade students from four schools who completed the survey, $40 \%$ were males and $60 \%$ were females. The majority of students $(56 \%)$ identified that they were not Hispanic/Latino and 37\% identified that they were white. However, relatively high numbers of students did not know whether they were Hispanic $(36 \%)$ or their race/ethnicity (23\%) (Table 2 ).

Two thirds of the participants reported that they ate fruits $(63.2 \%)$ or vegetables $(67.4 \%)$ less than twice per day with approximately one third indicating no consumptions of either fruits (27.4\%) or vegetables (28.4\%). However, the majority stated that they ate whole grain $(73.4 \%)$ or lean protein foods $(60.7 \%)$, or ate/drank dairy products $(77.9 \%)$ at least two times per day, with over one third consuming whole grains $(41.5 \%)$ or dairy $(36.8 \%)$ at least three times per day. Almost two thirds reported that they ate breakfast every day $(61.7 \%)$ and $59.0 \%$ said that they did not drink any sweetened beverages such as pop, punches, sport drink, or fruit flavored drink. Over 50\% (51.1\%) of the participants reported that they helped plan family meals at home at least 3 days per week. Self-efficacy scores trended to be high, with $89.7 \%$ to $98.0 \%$ of the participants having either high (very sure) or medium levels (somewhat sure) of self-efficacy on the relevant variables. Greater than $90 \%$ of the participants answered correctly on knowledge questions regarding healthy snack, healthy meal, healthy breakfast and healthy beverage; however, a majority of the participants had difficulties in questions on specific nutrients such as vitamin A (14.9\% scored correctly) and vitamin C (18.5\% scored correctly) (Table 2). Since our interest was to assess healthy eating behavior, self-efficacy, and knowledge among our study participants, results of physical activity related items ( 2 in behavior, 2 in self-efficacy, and 1 in knowledge section) were not included in the current study.

Table 3 demonstrates behavior and summary knowledge scores based on the self-efficacy profiles. Compared to the low self-efficacy group, the high self-efficacy group had significantly higher scores on eating fruits $(P=0.0009)$, 
Table 2 Demographics and healthy eating behavior, self-efficacy, and knowledge of study participants (the fifth grade students, $\mathbf{n}=\mathbf{9 8}$ )

\begin{tabular}{|c|c|}
\hline Demographics & $\mathrm{N}(\%)$ \\
\hline \multicolumn{2}{|l|}{ Gender } \\
\hline Male & $39(40)$ \\
\hline Female & $59(60)$ \\
\hline \multicolumn{2}{|l|}{ Race/ethnicity } \\
\hline American Indian or Alaska Native & $5(5)$ \\
\hline Asian & $9(9)$ \\
\hline Black or African American & $3(3)$ \\
\hline White/Caucasian & $36(37)$ \\
\hline Two or more races & $9(9)$ \\
\hline Other, not listed & $14(14)$ \\
\hline I don't know & $22(23)$ \\
\hline \multicolumn{2}{|l|}{ Hispanic/Latino } \\
\hline Yes & $8(8)$ \\
\hline No & $55(56)$ \\
\hline I don't know & $35(36)$ \\
\hline \multicolumn{2}{|l|}{ Behavior* } \\
\hline \multicolumn{2}{|l|}{ Eat fruits } \\
\hline None & $26(27.4)$ \\
\hline 1 time/day & $34(35.8)$ \\
\hline 2 times/day & $14(14.7)$ \\
\hline 3 or more times/day & $21(22.1)$ \\
\hline \multicolumn{2}{|l|}{ Eat vegetables } \\
\hline None & $27(28.4)$ \\
\hline 1 time/day & $37(39.0)$ \\
\hline 2 times/day & $21(22.1)$ \\
\hline 3 or more times/day & $10(10.5)$ \\
\hline \multicolumn{2}{|l|}{ Eat whole grains } \\
\hline None & $4(4.3)$ \\
\hline 1 time/day & $21(22.3)$ \\
\hline 2 times/day & $30(31.9)$ \\
\hline 3 or more times/day & $39(41.5)$ \\
\hline \multicolumn{2}{|l|}{ Eat lean protein } \\
\hline None & $9(9.6)$ \\
\hline 1 time/day & $28(29.8)$ \\
\hline 2 times/day & $34(36.2)$ \\
\hline 3 or more times/day & $23(24.5)$ \\
\hline \multicolumn{2}{|l|}{ Eat/drink dairy foods/drinks } \\
\hline None & $3(3.2)$ \\
\hline 1 time/day & $18(19.0)$ \\
\hline 2 times/day & $39(41.1)$ \\
\hline 3 or more times/day & $35(36.8)$ \\
\hline \multicolumn{2}{|l|}{ Eat French fries or chips } \\
\hline None & $57(60.0)$ \\
\hline
\end{tabular}


Table 2 Demographics and healthy eating behavior, self-efficacy, and knowledge of study participants (the fifth grade students, $\mathbf{n}=98$ ) (Continued)

\begin{tabular}{|c|c|}
\hline 1 time/day & $22(23.2)$ \\
\hline 2 times/day & $12(12.6)$ \\
\hline 3 or more times/day & $4(4.2)$ \\
\hline \multicolumn{2}{|c|}{ Drink sweetened beverages (pop, punches, sport drink, etc.) } \\
\hline None & $56(59)$. \\
\hline 1-2 time/day & $33(34.7)$ \\
\hline 3-4 times/day & $5(5.3)$ \\
\hline 5 or more times/day & $1(1.1)$ \\
\hline \multicolumn{2}{|c|}{ Eat doughnuts, cookies, brownies, cakes, candy } \\
\hline None & $32(33.7)$ \\
\hline 1-2 time/day & $52(54.7)$ \\
\hline 3-4 times/day & $8(8.4)$ \\
\hline 5 or more times/day & $3(3.2)$ \\
\hline \multicolumn{2}{|l|}{ Eat breakfast } \\
\hline 0 days/week & $2(2.1)$ \\
\hline 1-2 days/week & $5(5.3)$ \\
\hline 3-4 days/week & $6(6.4)$ \\
\hline 5-6 days/week & $23(24.5)$ \\
\hline 7 days/week & $58(61.7)$ \\
\hline \multicolumn{2}{|c|}{ Help plan family meals at home } \\
\hline 0 days/week & $19(20.2)$ \\
\hline 1-2 days/week & $27(28.7)$ \\
\hline 3-4 days/ week & $30(31.9)$ \\
\hline 5-6 days/week & $6(6.4)$ \\
\hline 7 days/week & $12(12.8)$ \\
\hline \multicolumn{2}{|l|}{ Self-efficacy ${ }^{\dagger}$} \\
\hline \multicolumn{2}{|l|}{ Identify a healthy meal } \\
\hline High & $55(56.7)$ \\
\hline Medium & $40(41.2)$ \\
\hline Low & $2(2.1)$ \\
\hline \multicolumn{2}{|c|}{ Choose a healthy meal at home } \\
\hline High & $61(62.9)$ \\
\hline Medium & $33(34.0)$ \\
\hline Low & $3(3.1)$ \\
\hline \multicolumn{2}{|c|}{ Choose a healthy meal at school } \\
\hline High & $53(55.2)$ \\
\hline Medium & $39(40.6)$ \\
\hline Low & $4(4.2)$ \\
\hline \multicolumn{2}{|c|}{ Choose a healthy meal when your friends do not } \\
\hline High & $34(35.8)$ \\
\hline Medium & $54(56.8)$ \\
\hline Low & $7(7.4)$ \\
\hline \multicolumn{2}{|c|}{ Choose a meal with all five food groups } \\
\hline High & $32(33.0)$ \\
\hline
\end{tabular}


Table 2 Demographics and healthy eating behavior, self-efficacy, and knowledge of study participants (the fifth grade students, $\mathbf{n}=98$ ) (Continued)

\begin{tabular}{|c|c|}
\hline Medium & $55(56.7)$ \\
\hline Low & $10(10.3)$ \\
\hline \multicolumn{2}{|c|}{ Plan a meal with at least three different food groups } \\
\hline High & $63(65.0)$ \\
\hline Medium & $29(29.9)$ \\
\hline Low & $5(5.1)$ \\
\hline \multicolumn{2}{|l|}{ Choose a healthy snack } \\
\hline High & $64(66.7)$ \\
\hline Medium & $30(31.3)$ \\
\hline Low & $2(2.1)$ \\
\hline \multicolumn{2}{|l|}{ Eat breakfast every morning } \\
\hline High & $62(64.6)$ \\
\hline Medium & $28(29.2)$ \\
\hline Low & $6(6.3)$ \\
\hline Knowledge* & $\%$ of the participants answered correctly \\
\hline Healthy snack & 92.9 \\
\hline Healthy meal & 79.6 \\
\hline Healthy breakfast & 99.0 \\
\hline Healthy beverage & 99.0 \\
\hline Digestion & 81.4 \\
\hline Nutrients like carbohydrate & 55.1 \\
\hline Nutrients like protein & 85.6 \\
\hline Nutrients like calcium & 82.3 \\
\hline Nutrients like vitamin A & 14.9 \\
\hline Nutrients like vitamin $C$ & 18.5 \\
\hline
\end{tabular}

${ }^{*} 1$ to 9 participants had missing data on the behavior, self-efficacy, or knowledge variables.

${ }^{\dagger} H$ High self-efficacy, very sure; medium self-efficacy, somewhat sure; low self-efficacy, not sure at all.

consuming dairy products $(\mathrm{P}=0.009)$, eating breakfast $(\mathrm{P}=0.008)$ and helping plan family meals at home $(\mathrm{P}=$ 0.0006), and higher summary behavior scores on healthy eating $(\mathrm{P}=0.001)$. There were no differences in summary scores of nutrition knowledge between the two groups $(P=0.74)$. Summary scores of self-efficacy and behavior were positively correlated $(\mathrm{r}=0.40, \mathrm{P}=0.0001)$; however, summary knowledge scores were not associated with selfefficacy $(\mathrm{r}=0.02, \mathrm{P}=0.88)$ or behavior summary scores $(\mathrm{r}=0.14, \mathrm{P}=0.23)$.

Factor analysis results for healthy eating related behavior and self-efficacy variables are shown in Table 4. It appeared that the behavior or self-efficacy construct each was associated with three main underlying factors: consuming healthy foods (Factor 1), consuming unhealthy foods (Factor 2), and eating breakfast and eating lean protein (Factor 3) for behavior; identifying/choosing healthy meals and snacks (Factor 1), planning/choosing a meal with different food groups (Factor 2), and eating breakfast every morning and choosing healthy meals at school (Factor 3) for self-efficacy. For behavior, Factor 1 of consuming healthy foods captured most of the variance $(22.07 \%)$, and eating fruits (factor loading, 0.74) and vegetables (factor loading, 0.76) had the strongest associations with this latent variable (Factor 1). Factor 1 was also highly associated with consuming dairy products (factor loading, 0.63 ) and eating whole grains (factor loading, 0.53). In addition, drinking sweetened beverages (factor loading, 0.74) and eating French fries or chips (factor loading, 0.72) were strongly correlated to Factor 2 of consuming unhealthy foods. With respect to self-efficacy, a higher portion of the variance was explained by Factor 1 of identifying/ choosing healthy meals and snacks (27.53\%). Choosing a healthy meal at home (factor loading, 0.79) and choosing a healthy meal when your friends do not (factor loading, 0.79 ) had the strongest correlations with this factor.

\section{Discussion}

Results from this study indicate that the Healthy Habits Survey is both a valid and useful tool to measure 
Table 3 Scores of heathy eating behaviors and nutrition knowledge based on self-efficacy profiles of study participants (the fifth grade students)

\begin{tabular}{|c|c|c|c|}
\hline & \multicolumn{2}{|l|}{ Scores* $($ mean \pm SD) } & \multirow[b]{2}{*}{ P value $^{\dagger}$} \\
\hline & $\begin{array}{l}\text { Low self-efficacy* } \\
(n=38)\end{array}$ & $\begin{array}{l}\text { High self-efficacy* } \\
(n=39)\end{array}$ & \\
\hline Summary self-efficacy & $11.00 \pm 0.91$ & $15.89 \pm 2.00$ & $<0.0001$ \\
\hline \multicolumn{4}{|l|}{ Behavior } \\
\hline Eat vegetable & $2.08 \pm 1.02$ & $2.23 \pm 0.96$ & 0.50 \\
\hline Eat fruits & $1.94 \pm 1.01$ & $2.76 \pm 1.06$ & 0.0009 \\
\hline Eat whole grains & $3.13 \pm 0.84$ & $3.21 \pm 0.86$ & 0.71 \\
\hline Eat lean protein & $2.62 \pm 1.01$ & $2.92 \pm 0.77$ & 0.15 \\
\hline Eat dairy & $2.97 \pm 0.88$ & $3.44 \pm 0.60$ & 0.009 \\
\hline Drink less sweetened beverages (soda, punches, etc.) & $3.61 \pm 0.59$ & $3.41 \pm 0.72$ & 0.20 \\
\hline Eat less French fries or chips & $3.50 \pm 0.73$ & $3.33 \pm 0.90$ & 0.37 \\
\hline Eat less donuts, cookies, brownies, cakes, candies & $3.08 \pm 0.75$ & $3.33 \pm 0.62$ & 0.11 \\
\hline Eat breakfast & $4.08 \pm 1.22$ & $4.68 \pm 0.57$ & 0.008 \\
\hline Help plan family meals at home & $2.16 \pm 1.08$ & $3.10 \pm 1.21$ & 0.0006 \\
\hline Summary behavior ${ }^{\ddagger}$ & $32.75 \pm 4.17$ & $35.92 \pm 3.75$ & 0.001 \\
\hline Summary nutrition Knowledge ${ }^{\ddagger}$ & $7.84 \pm 1.37$ & $7.74 \pm 1.33$ & 0.74 \\
\hline
\end{tabular}

knowledge, behavior, and self-efficacy for SCT-based nutrition education programs among 9-12 year old students. Our study also suggested that participants with higher self-efficacy scores were more likely to report healthful eating behaviors.

The unique aspect of this survey instrument is the selfefficacy component. Self-efficacy is one of the important constructs of the SCT and limited surveys on nutrition education programs address this issue. Even within the existing instruments, none have assessed self-efficacy for a wide array of nutrition-related topics among children ages 9 to 12 years. Gimme 5, a SCT-based curriculum focusing on fruits and vegetables evaluated the impact on selfefficacy. The 22-item survey instrument, created for the target population of third to fifth grade students had an average alpha reliability of 0.90 , but it only focused on assessing self-efficacy for eating fruits and vegetables [14]. "Smart Bodies" is another educational intervention based upon the SCT, targeting fourth and fifth grade students [18]. Similar to Gimme 5, the survey instrument demonstrated high alpha reliabilities for pre $(0.92)$ and post lessons (0.90), but also had its main focus on fruits and vegetables [18]. The Coordinated Approach to Child Health $(\mathrm{CATCH})$ study utilized modified items for selfefficacy from the Health Behavior Questionnaire; however, these items focus more on salt and fat intake and physical activity rather than a broad array of items [13]. In addition, these studies did not assess the long-term impact of the respective programs $[13,14,18]$. The Integrated $\mathrm{Nu}$ trition and Physical Activity program conducted a longterm follow-up of second grade students in the fifth to eighth grade, examining self-efficacy on food preparation and identification of foods with fat and found alpha reliabilities ranging from 0.72-0.75 [31], which were similar to our results (Cronbach's alpha: initial survey $=0.67$; revised survey $=0.70$ ). The reliability results (Cronbach's alpha: initial survey $=0.60$; revised survey $=0.71$ ) for the behavior section were consistent with what we hypothesized since all of the items in this section were taken from existing, validated instruments [25,26].

The internal consistency/reliability of knowledge questions appeared to be lower than hypothesized (Cronbach's alpha: initial survey $=0.41$; revised survey $=0.56$ ) since a majority of the knowledge questions were taken verbatim or modified from existing, validated instruments. There are several possible explanations. The difficulty level of the knowledge questions might be higher for the students who had not received supplementary nutrition education, which was the case for our pilot participants. Our study population and the populations in the original studies from which these questions were taken may have been inherently different in certain demographics such as race/ ethnicity, gender, and socioeconomic status. In addition, we measured a broad range of knowledge including 
Table 4 Factor analysis for healthy eating behavior and self-efficacy among study participants (the fifth grade students, $\mathbf{n}=98$ )

\begin{tabular}{|c|c|c|c|}
\hline & Factor $1^{\dagger}$ & Factor $2^{\dagger}$ & Factor $3^{\dagger}$ \\
\hline \multicolumn{4}{|l|}{ Behavior variables } \\
\hline \multicolumn{4}{|l|}{ Factor loading* } \\
\hline Eat vegetable & 0.76 & -0.07 & 0.09 \\
\hline Eat fruits & 0.74 & -0.01 & 0.30 \\
\hline Eat whole grains & 0.53 & 0.11 & 0.35 \\
\hline Eat lean protein & 0.35 & 0.05 & 0.65 \\
\hline Eat/drink dairy & 0.63 & 0.32 & -0.08 \\
\hline Drink sweetened beverages (soda, punches, etc.) & 0.22 & 0.74 & -0.28 \\
\hline Eat French fries or chips & 0.03 & 0.72 & 0.16 \\
\hline Eat donuts, cookies, brownies, cakes, candies & -0.07 & 0.65 & 0.47 \\
\hline Eat breakfast & 0.09 & 0.03 & 0.67 \\
\hline \multicolumn{4}{|l|}{ Variance explained } \\
\hline Total & 1.99 & 1.60 & 1.41 \\
\hline$\%$ of variance & 22.07 & 17.78 & 15.76 \\
\hline \multicolumn{4}{|l|}{ Self-efficacy variables } \\
\hline \multicolumn{4}{|l|}{ Factor loading* } \\
\hline Identify a healthy meal & 0.68 & -0.04 & 0.21 \\
\hline Choose a healthy meal at home & 0.79 & 0.15 & 0.01 \\
\hline Choose a healthy meal at school & 0.38 & 0.20 & 0.62 \\
\hline Choose a healthy meal when your friends do not & 0.79 & 0.05 & -0.06 \\
\hline Choose a meal with all five food groups & 0.20 & 0.69 & 0.25 \\
\hline Plan a meal with at least three different food groups & -0.01 & 0.82 & -0.23 \\
\hline Choose a healthy snack & 0.57 & 0.36 & 0.08 \\
\hline Eat breakfast every morning & -0.10 & -0.12 & 0.84 \\
\hline \multicolumn{4}{|l|}{ Variance explained } \\
\hline Total & 2.20 & 1.35 & 1.25 \\
\hline$\%$ of variance & 27.53 & 16.86 & 15.60 \\
\hline
\end{tabular}

*Factor loading: Correlation of each behavior or self-efficacy variable with each factor using factor analysis. Higher absolute values represent higher correlations; "1" or "-1" represents the maximal correlation strength.

${ }^{\dagger}$ For behavior: Factor 1 = consuming healthy foods, Factor $2=$ consuming unhealthy foods; Factor $3=$ eating breakfast and consuming lean protein; for self-efficacy, Factor $1=$ identifying/choosing healthy meals and snacks, Factor $2=$ choosing/planning a meal with different food groups, Factor $3=$ eating breakfast every morning and choosing healthy meals at school.

knowledge necessary to conduct nutrition related health behaviors and knowledge of certain nutrients, such as carbohydrates and vitamins. The reasons for including the measures of the more specific nutrition knowledge were: 1) knowing the benefits of vitamins and carbohydrates, for instance, would demonstrate the importance for children to eat a healthy and balanced meal; and 2) our knowledge scale was created for assessing GHK where health benefits of carbohydrate and vitamins were taught in the curriculum.

In our study, self-efficacy and behavior (for healthy eating) summary scores were positively associated; however, there were no associations of knowledge scores with behavior or self-efficacy. The current results demonstrated that participants with high self-efficacy also had higher behavior scores (eat fruits, eat/drink dairy products, eat breakfast, help plan family meals at home, and summary behavior scores) than those with low selfefficacy, suggesting that self-efficacy may be more relevant than knowledge in terms of influencing children's eating behaviors. However, the low reliability of Cronbach's alpha for knowledge may have influenced the relationship between knowledge and behavior. Our findings were consistent with the SCT, which suggests that self-efficacy plays an important role in an individual's behavioral changes [17]. Indeed, Ramirez et al. found self-efficacy to be a predictor of physical activity in fourth to sixth grade students [32]. Results from Farm to School programs have also demonstrated an association between behavior and selfefficacy in fourth to sixth grade students based on self- 
report data [33]. Factor analysis results suggest that consuming healthy foods and choosing/identifying healthy meals and snacks were key underlying factors for behavior and self-efficacy constructs, respectively. It also suggested that eating fruit and vegetables was more relevant in terms of the consumption of healthy foods.

The observed significant differences in behavior variables regarding fruit or dairy intakes, and eating breakfast between participants with high and low self-efficacy scores may be explained in part by the ongoing efforts made by the schools in concert with several national programs such as the United States Department of Agriculture's Fresh Fruit and Vegetable Program [34], the Healthy, HungerFree Kids Act of 2010 [35], and the National School Lunch and School Breakfast Programs [36]. These efforts increase the accessibility of fruits, dairy foods, and breakfast in the school environment, thereby raising self-efficacy of improving these eating behaviors among the students, leading to enhanced performance of target behavior. However, it appeared that self-efficacy did not influence students' vegetable intake even though making fresh vegetables more accessible was also part of the efforts from some of these programs [34,35]. It is possible that the taste of fresh fruits was more appealing to children as compared to that of fresh vegetables. Future studies with a larger sample size are necessary to confirm our findings.

Two thirds of the fifth grade students in our study reported that they either ate fruits or vegetables only once or did not eat them at all on a typical day, with approximately half indicating no consumptions of any of these foods. Although the current results need to be further confirmed in the studies in which the participants are randomly drawn from a large population, they in general, reflect a pattern of dietary behaviors among children in the Midwestern area since the four elementary schools involved in our study had similar demographics (i.e., race/ethnicities, socioeconomic status of the schools) compared to the overall student population in the area. Our findings that a relatively high proportion of the fifth grade students tended to consume less or no fruits or vegetables suggest that strategic interventions are needed to address this ongoing problem among elementary school children.

The current investigation is the first study which developed and validated a survey instrument that includes self-efficacy assessment for an educational program covering a variety of nutrition-related topics for older elementary school students ( 9 to 12 years). There are several strengths of the study. The study population was diverse in terms of race/ethnicity and school socioeconomic status, providing a wide range of perspectives that reflect both the Title I ( $\geq 40 \%$ students receiving free or reduced price school meals) and non-Title I $(<40 \%$ students receiving free or reduced price school meals) schools that this instrument will be used to evaluate in the future.
The survey instrument developed in our study was validated using various methods, including content validity, face validity, and internal consistency reliability. Furthermore, the constructs of the survey were strengthened by the significant correlation between behavior and selfefficacy scores and the factor analysis outcomes which identified the key patterns related to healthy eating behaviors and self-efficacy. Additionally, the inclusion of measurements of behavior and self-efficacy and the necessary knowledge to perform nutrition related health behaviors would allow this instrument to apply to many SCT-based nutrition programs beyond GHK; however, as with many surveys, it may need to be modified to fit into each individual program and the specific population associated with the program.

Our study has limitations. The participants (fifth grade students) were recruited from schools that had never been exposed to any nutrition interventions. Therefore, the pilot testing results, particularly for knowledge, may not be generalized among other fifth grade students who have received supplementary nutrition education. Also, due to the nature of convenience sampling, our findings regarding children's dietary behaviors may not completely represent the entire fifth grade student population; nevertheless, the current study population varied in race/ethnicity and socio-economic status with a range of $6.5 \%$ to $47.3 \%$ of the students among the four schools involved receiving free or reduced price school meals. Furthermore, although our measures were validated, additional assessments such as food diaries/records or behavioral observation may help provide a more accurate evaluation of behaviors and reduce self-report/response bias, particularly among children. There may also have been issues with common method variance, though we employed different means to minimize this type of bias, including the use of different scale types for different constructs, incorporation of both negative and positive behavior items, use of familiar survey format, and assurance of anonymity to encourage truthful answers. Lastly, according to the qualitative results, children had difficulty with demographic questions and the feeling of being rushed and missing items, leading to potential information bias. For future implementation of this instrument among children of this age group, we recommend to simplify demographic items and remind students to check every page of their surveys when finishing so that all the survey questions will be completed.

\section{Conclusion}

The current results indicate that the Healthy Habits Survey is a valid and useful tool to evaluate the effectiveness of SCT-based nutrition education programs that teach broad knowledge of nutrition and physical activity among older elementary school students. In addition, our results suggest 
that participants with higher self-efficacy scores were also associated with higher behavior scores for healthy eating. However, the fact that relatively high proportions of the fifth grade students in our study had low intakes of fruits or vegetables warrants strategic interventions to facilitate the behavior change.

\section{Competing interests}

The authors declare that they have no competing interests.

\section{Authors' contributions}

All of the authors made substantial contributions to the study concept and design and analysis and interpretation of the data. Specifically, EH designed the study, recruited the participants, developed the instrument, collected and analyzed results, and was the primary author of the text. WC designed the study and analyzed data. WK was instrumental in the design of the original program. JA originally conceived of and designed the study. All authors contributed to preparation of the manuscript and read and approved the final manuscript.

\section{Acknowledgement}

The authors would like to thank the staff at the University of Nebraska-Lincoln Extension and Lancaster County Extension for their valuable feedback as content experts. This project was conducted as a part of the USDA NIFA Growing Healthy Kids through Health Communities grant; 2011-67001-30011.

\section{Author details}

${ }^{1}$ Department of Nutrition and Health Sciences, University of Nebraska-Lincoln, 110 Leverton Hall, Lincoln, NE 68583, USA. ${ }^{2}$ Nutrition and Dietetics, University of North Dakota, Grand Forks, USA.

Received: 9 October 2014 Accepted: 26 March 2015

Published online: 09 April 2015

\section{References}

1. Levi J, Segal L, Laurent R, Lang A, Rayburn J. F as in Fat Report. Robert Wood Johnson Foundation; 2012. http://healthyamericans.org/assets/files/ TFAH2012FasInFatFnIRv.pdf. Accessed 20 March 2015.

2. Steinbeck K. Childhood obesity: consequences and complications. Clin Obes Adults Child. 2010;3:392-407.

3. Boulet LP. Asthma and obesity. Clin Exp Allergy. 2013;43(1):8-21.

4. Glanz K, Rimer B, Viswanath K. Health Behavior and Health Education: Theory Research and Practice. San Francisco: Jossey-Bass Publishers; 2008.

5. Nixon CA, Moore HJ, Douthwaite W, Gibson EL, Vogele C, Kreichauf S, et al. Identifying effective behavioural models and behaviour change strategies underpinning preschool- and school-based obesity prevention interventions aimed at 4-6-year-olds: a systematic review. Obes Rev. 2012;13 Suppl 1:106-17.

6. Dewar DL, Morgan PJ, Plotnikoff RC, Okely AD, Batterham M, Lubans DR. Exploring changes in physical activity, sedentary behaviors and hypothesized mediators in the NEAT girls group randomized controlled trial. J Sci Med Sport. 2014;17(1):39-46.

7. Dzewaltowski DA, Estabrooks PA, Welk G, Hill J, Milliken G, Karteroliotis K, et al. Healthy youth places: a randomized controlled trial to determine the effectiveness of facilitating adult and youth leaders to promote physical activity and fruit and vegetable consumption in middle schools. Health Educ Behav. 2009;36(3):583-600.

8. Branscum P, Sharma M, Wang LL, Wilson B, Rojas-Guyler L. A true challenge for any superhero: an evaluation of a comic book obesity prevention program. Community Health. 2013;36(1):63-76.

9. Branscum P, Kaye G, Warner J. Impacting dietary behaviors of children form low income communities: an evaluation of a theory-based nutrition education program. Calif J Health Promot. 2013;11(2):43-52.

10. Rosenkranz RR, Behrens TK, Dzewaltowski DA. A group-randomized controlled trail for health promotion in Girl Scouts: healthier troops in a SNAP (scouting nutrition \& activity program). BMC Public Health. 2010;10(81):1-13.

11. Thompson D, Baranowski T, Baranowski J, Cullen K, Jago R, Watson K, et al. Boy Scout 5-a-day badge: outcome results of a troop and internet intervention. Prev Med. 2009;49:518-26.
12. Black MM, Hager ER, Le K, Anliker J, Arteaga S, DiClemente C, et al. Challenge! Health promotion/obesity prevention mentorship model among urban, black adolescents. Pediatrics. 2010;126(2):280-8.

13. Kelder S, Hoelscher DM, Barroso CS, Walker JL, Cribb P, Hu S. The CATCH Kids Club: a pilot after-school study for improving elementary students' nutrition and physical activity. Public Health Nutr. 2005;8(2):133-40.

14. Baranowski T, Davis M, Resnicow K, Baranowski J, Doyle C, Lin LS, et al. Gimme 5 fruit, juice, and vegetables for fun and health: outcome evaluation. Health Educ Behav. 2000;27(1):96-111.

15. Townsend MS, Johns M, Shilts MK, Farfan-Ramirez L. Evaluation of a USDA nutrition education program for low-income youth. J Nutr Educ Behav. 2006;38(1):30-41.

16. De Bourdeaudhuij I, Klepp Kl, Due P, Rodrigo CP, de Almeida M, Wind M, et al. Reliability and validity of a questionnaire to measure personal, social and environmental correlates of fruit and vegetable intake in 10-11-year-old children in five European countries. Public Health Nutr. 2005;8(2):189-200.

17. Bandura A. Health promotion by social cognitive means. Health Educ Behav. 2004;31(2):143-64.

18. Tuuri G, Zanovec M, Silverman L, Geaghan J, Solmon M, Holston D, et al. "Smart Bodies" school wellness program increased children's knowledge of healthy nutrition practices and self-efficacy to consume fruit and vegetables. Appetite. 2009;52(2):445-51.

19. Edmundson E, Parcel GS, Perry CL, Feldman HA, Smyth M, Johnson CC, et al. The effects of the child and adolescent trial for cardiovascular health intervention on psychosocial determinants of cardiovascular disease risk behavior among third-grade students. Am J Health Promot. 1996;10(3):217-25.

20. Hernandez-Garbanzo Y, Brosh J, Serrano EL, Cason KL, Bhattarai R. Psychosocial measures used to assess the effectiveness of school-based nutrition education programs: review and analysis of self-report instruments for children 8 to 12 years old. J Nutr Educ Behav. 2013;45(5):392-403.

21. Contento IR, Randell JS, Basch CE. Review and analysis of evaluation measures used in nutrition education intervention research. J Nutr Educ Behav. 2002;34(1):2-25.

22. DiClemente R, Salazar LF, Crosby RA. Health Behavior Theory for Public Health: Principles, Foundations, and Applications. Burlington: Jones and Bartlett Learning; 2011.

23. Edberg M. Essentials of Health Behavior. Burlington: Jones and Bartlett Learning; 2015.

24. McKenzie JF, Neiger BL, Thackeray R. Health Promotion Programs. Glenview: Pearson Education, Inc; 2013.

25. Jensen B, Kattelmann K, Ren C, Wey H. The efficacy of KidQuest: a nutrition and physical activity curriculum for $5^{\text {th }}$ and 6 th grade youth. J Extension. 2009;47(3):1-16.

26. The Network for a Healthy California. In: Compendium of Surveys for Nutrition Education and Obesity Prevention. California Department of Public Health; 2012. http://www.cdph.ca.gov/programs/cpns/Documents/Compendium\% 20of\%20Surveys.pdf. Accessed January 31, 2014.

27. Children and Youth Evaluation Tools and Documentation. In. Wisconsin Nutrition Education Program. Cooperative Extension Website. http://www. uwex.edu/ces/wnep/ncyouth/. Accessed January 31, 2014.

28. Struempler BJ, Raby A. Pizza Please: an interactive nutrition evaluation for second and third grade students. J Nutr Educ Behav. 2005;37(2):94-5.

29. Readability Formulas. ReadabilityFormulas.com. http://www. readabilityformulas.com/free-readability-formula-tests.php. Accessed September 16, 2013.

30. Rubio DM, Berg-Weger J, Tebb SS, Lee ES, Rauch S. Objectifying content validity: conducting a content validity study in social work research. Soc Work Res. 2003;27(2):94-104.

31. Puma J, Romaniello C, Crane L, Scarbro S, Belansky E, Marshall JA. Long-term student outcomes of the Integrated Nutrition and Physical Activity Program. J Nutr Educ Behav. 2013;45(6):635-42.

32. Ramirez E, Hodges Kulinna P, Cothran D. Constructs of physical activity behaviour in children: the usefulness of social cognitive theory. Psychol Sport Exerc. 2012;13:303-10.

33. Roche E, Conner D, Kolodinsky JM, Buckwalter E, Berlin L, Powers A. Social cognitive theory as a framework for considering farm to school programming. Childhood Obes. 2012;8(4):357-63. 
34. Fresh Fruit and Vegetable Program: A Handbook for Schools. United States Department of Agriculture. http://www.fns.usda.gov/sites/default/files/ handbook.pdf. Accessed December 12, 2015.

35. School Meals. Healthy Hunger-Free Kids Act. United States Department of Agriculture. http://www.fns.usda.gov/school-meals/healthy-hunger-free-kidsact. Accessed December 12, 2015.

36. School Breakfast Program. United States of Agriculture. http://www.fns.usda. gov/sbp/school-breakfast-program-sbp. Access December 12, 2015

Submit your next manuscript to BioMed Central and take full advantage of:

- Convenient online submission

- Thorough peer review

- No space constraints or color figure charges

- Immediate publication on acceptance

- Inclusion in PubMed, CAS, Scopus and Google Scholar

- Research which is freely available for redistribution 